\title{
The Journal and Originality
}

\author{
Eelco F. M. Wijdicks
}

Published online: 9 January 2013

(c) Springer Science+Business Media New York 2013

When you click on the journal's content or open up the hard cover of Neurocritical Care, you expect to see something new or even something provocative. And yet there are less earth shaking issues. That is the hard truth, and it applies to all journals-great and small. Every editor would like to see the most original work by the most original study group, and only the journals with the highest impact factor can count on it. To publish an important first observation that may go on to become a landmark in the literature of neurocritical care is a lofty goal, but something we could work toward. Although the architect, Ludwig Mies van der Rohe, famously said "It is better to be good than to be original", in our continuously growing specialty, we have to be both.

Skeptics will point out that all concepts have been articulated before. Just go back far enough, and you will find it. They would say just look at renewed interest in the spreading depression already proposed by Leão in 1944How about penicillin neurotoxicity now more often seen as cefepime neurotoxicity. I need not remind this readership that before we diagnosed cerebral salt wasting, we had SIADH and even before that-guess what-cerebral salt wasting.

Can we still be original? We should forcefully reject the "everything has been done before" argument. I continue to be pleasantly surprised by the highly interesting submissions over the years. In our field, advancement could come with a new original description, but this may also include an important rarity that has immediate consequences for

E. F. M. Wijdicks ( $₫)$

Division of Critical Care Neurology, Mayo Clinic,

Rochester, USA

e-mail:wijde@mayo.edu management. There is no shortage of careful clinical descriptions of difficult patients, a new treatment, the first review of a major topic, and a never seen before neuroimage. We continue to publish papers that may seem a niche interest to some, but to others, their life's work.

Therefore, authors submitting material to the journal have noticed that although their papers are important observations, the work has been rejected because it lacks novelty. I have been rejecting papers that are not advancing our knowledge, are much of the same, and certainly studies that do nothing but confirming the obvious. Also, over the years, manuscripts have been rejected without external review. I have taken the liberty to reject papers that fail to meet our increasing higher standards, and papers that are clearly serving the interest of the industry. I have, to the best of my knowledge, not rejected a well-executed manuscript but reconsidered if I was wrong or too quick on the draw. In truth, the originality of a paper remains our most important measure. Editors would want to avoid significant time spent on very weak manuscripts.

Does this include case reports-the bane of journals? Case reports are rarely cited and may reduce impact factor if other worthwhile papers - that could be cited - are not published. Imagine a case that leads to a new concept or insight. We do not want to miss that.

So how could we define "originality" in a manuscript? Does it all have to be pristinely novel? What is synonymous with originality? One could say it should contain an innovative thought, a probing study into a new area, a rarely photographed or video-recorded clinical sign and even more closer to the bedside a validated new tool. Unoriginal does not need a definition, and we all recognize shopworn and uninspiring material. 
Our journal has an important goal: to keep you up-to-date with the rapidly changing field. Our papers are increasingly more commonly cited by distinguished scholars, and that will sustain our quality. Only if we write original material will we thrive as academic neurointensivists.

This year, 2013, will be our 10th year of journal publishing; and it comes close after the 10-year celebration of the Neurocritical Care Society. We should be pleased with how the Journal is progressing. Over the last 10 years, we have seen a significant increase in the number of submissions, and there is no evidence of leveling off. You do not even have to be a neurointensivist to appreciate the journal, but you have to be eager to gather knowledge on how to care best for these unfortunate patients. I promise this year will see exciting new topics that will advance the care of our patients with acute neurologic and neurosurgical disease. Again I would like to thank the ad hoc reviewers listed below. It requires an effort and a commitment to the greater good to timely review papers, and these reviewers and the editorial board have been of great help identifying papers that are worth publishing.

\section{Ad hoc reviewers}

Nicholas Abend
Opeolu Adeoye
Imoigele Aisiku
Venkatesh Aiyagari
Paul Akins
George Alexiou
Fabio Andrade
Safdar Ansari
Fahad Aziz
Bulent Bakar
Saikat Bandyopadhyay
Helen Barkan
Mustafa Baskaya
Antoine Baumann
Ronny Beer
Michael Bell
Randy Bell
Francis Bernard
Eric Bershad
Federico Bilotta
Kathleen Bledsoe
Michel Bojanowski
Eric Bourekas
Ansgar Brambrink
Raf Brouns
Ross Bullock
Peter Campbell
Norbert Campeau

Raphael Carandang

Gianluca Castellani

Julio Chalela

Jeff Chen

Zhi Chen

Soon Ho Cheong

Arturo Chieregato

Charmaine Childs

Harry Cloft

Thiago Coelho

Jonathan Coles

Alfredo Conti

Steve Cordina

Claire Creutzfeldt

Salvador Cruz-Flores

Marek Czosnyka

Jean de Oliveira

Rajat Dhar

Jens Dreier

Christopher Eddleman

Muhammad Farooq

Matthew Flaherty

Jeffrey Fletcher

Kostas Fountas

Isabel Fragata

Jennifer Fugate

Sunil Furtado

Daniel Godoy

Kenneth Gorson

David Greer

Hillary Grocott

Bradley Gross

Ai Guo

John Halperin

Khalid Hanafy

Jacob Hansen-Schwartz

Angela Hays

Raimund Helbok

Matthieu Henry-Lagarrigue

Ji Hoe Heo

Archana Hinduja

Holly Hinson

Lawrence Hirsch

Damian Holliman

Stephen Huff

Andreas Hug

Ferdinand Hui

Matthias Jaeger

Michael James

Tariq Janjua

Sriganesh Kamath

Gregory Kapinos

Vasilios Katsaridis 
Salah Keyrouz

May Kim-Tenser

Matthias Klein

Matthew Koenig

Andrew Kofke

Bradley Kolls

Erwin Kompanje

Stephane Kremer

John Kuluz

Gyanendra Kumar

Avinash Kumar

Sui Sum Kung

Julius Gene Latorre

Andrea Lavinio

Kennith Layton

Christos Lazaridis

Stephane Legriel

Abhijit Lele

Peter LeRoux

Joshua Levine

David Liebeskind

Mikls Lipcsey

Juan Llompart-Pou

Yahia Lodi

Dana Lustbader

Silvia Marino

Anna Teresa Mazzeo

Shearwood McClelland III

Alexander McKinney

Ivan Mikolaenko

Chad Miller

Susanne Mink

Michael Moussouttas

Susanne Muehlschlegel

Michael Mullen

Tatsushi Mutoh

Masao Nagayama

Andrew Naidech

Kazuma Nakagawa

Rahul Nanchal

Jayashree Narayanan

Ron Neyens

Ivan $\mathrm{Ng}$

Thanh Nguyen

Marc Nuwer

Paul Nyquist

Kristine O'Phelan

Mauro Oddo

Matsatoshi ohnishi

Juan Padilla

Konstantinos Paterakis

Gustavo Patriota

Konstantin Popugaev
Virginia Prendergast

Javier Provencio J.

Corina Puppo

Eric Racine

Girija Rath

Rahul Rathakrishnan

Fred Rincon

Carlos Romero

Jeffrey Rosenfeld

Anand Rughani

Farid Sadaka

Monica Saini

Lauren Sansing

Asita Sarrafzadeh

Aarti Sarwal

Martin Savard

Clemens Schirmer

Michael Schneck

Sebastian Schulz-Stubner

Stefan Schwarz

L Keith Scott

David Seder

A. K. Shah

Deepak Sharma

Kevin Sheth

Jody Short

Lori Shutter

John Sims

Vineeta Singh

Martin Smith

Stephen Smith

Romain Sonneville

Erik St. Louis

Sherman Stein

Deborah Stein

Erik $\mathrm{Su}$

Marek Sykora

Silvio Taccone Fabio

John Tayek

Samuel Tisherman

Michel Torbey

Diederik van de Beek

Walter van den Bergh

Hendrik van der Worp

Nicolas Velasco

Chethan Venkatasubba Rao

Mervyn Vergouwen

Deepti Vibha

Arasch Wafaisade

Marjorie Wang

David Wang

Adam Webb

Nicolas Weiss 
Linda Wendell

Christine Wijman

Elzbieta Wirkowski

Stefan Wolf

Ching-Tang Wu
Qing-Wu Yang

Gabriel Zada

Allyson Zazulia

Wendy Ziai

Alexander Zubkov 